\title{
AVALIAÇÃO DA VANILINA COMO AGENTE ANTIMICROBIANO EM ABACAXI 'PÉROLA' MINIMAMENTE PROCESSADO'
}

\author{
Lucimara Rogéria ANTONIOLLI ${ }^{2 *}$, Benedito Carlos BENEDETTI ${ }^{2}$, \\ Men de Sá Moreira de SOUZA FILHO ${ }^{3}$, Maria de Fátima BORGES ${ }^{3}$
}

\section{RESUMO}

Procurou-se avaliar os efeitos da vanilina como agente antimicrobiano, bem como o nível de injúria física como fator de contaminação inicial em abacaxi (Ananas comosus (L.) Meer) cv. Pérola minimamente processado. Fatias e cubos foram obtidos a partir de frutos sanitizados, descascados e fatiados mecanicamente. Os dois tipos de corte foram imersos, separadamente, em água (controle) ou soluções de vanilina 3000 ou $5000 \mathrm{mg} . \mathrm{L}^{-1}$, durante 30 segundos. Após período de repouso, para drenagem do excesso de líquido, foram acondicionados em embalagens de polietileno tereftalato e mantidos à temperatura de $4 \pm 1{ }^{\circ} \mathrm{C}$ durante 12 dias. As análises microbiológicas, realizadas em intervalos de 3 dias, envolveram a contagem de microrganismos aeróbios mesófilos e de bolores e leveduras e a determinação de coliformes totais e fecais. A utilização de vanilina mostrou-se ineficiente no controle do crescimento da população de microrganismos aeróbios mesófilos e de bolores e leveduras em abacaxi 'Pérola' minimamente processado. O maior nível de injúrias físicas efetuado nos cubos parece favorecer a contaminação inicial do produto.

Palavras-chave: Ananas comosus; processamento mínimo; antimicrobiano natural; armazenamento refrigerado.

\section{SUMMARY}

EVALUATION OF VANILLIN AS AN ANTIMICROBIAL AGENT ON FRESH-CUT 'PÉROLA' PINEAPPLE. The purpose of this research was to evaluate the effects of vanillin as an antimicrobial agent, as well as the relationship between the injury degree and initial contamination in fresh-cut pineapple (Ananas comosus (L.) Meer) cv. Pérola. Slices and cubes were obtained from whole fruits that were mechanically peeled and sliced after sanitization. Both kinds of cutting were dipped in pure water (control) or vanillin solutions 3000 or $5000 \mathrm{mg} . \mathrm{L}^{-1}$, for 30 seconds. After that, the liquid was drained, slices and cubes were placed in polyethylene terephtalate packages and stored at $4 \pm 1^{\circ} \mathrm{C}$ during 12 days. Microbiological analyses were carried out every 3 days and involved mesophile aerobic counts, molds and yeasts and total and fecal coliforms determination. The use of vanillin was inefficient for the control of mesophile aerobic and molds and yeasts growth on fresh-cut 'Pérola' pineapple. It seems that, the greater degree of injuries made in the cubes had favored the initial contamination of the product.

Keywords: Ananas comosus; fresh-cut; natural antimicrobial; cold storage.

\section{1 - INTRODUÇÃO}

A demanda crescente por produtos hortícolas minimamente processados (MP) justifica-se pela preservação do frescor e da qualidade nutricional, associada à conveniência proporcionada por tais alimentos. Dentre as frutas tropicais com grande potencial de comercialização na forma de minimamente processado, destacase o abacaxi, em função de sua excelente qualidade organoléptica e de certa dificuldade para consumo imediato, decorrente de sua própria estrutura morfológica.

A qualidade e a segurança microbiológica devem ser consideradas como prioridade no processamento minimo de frutas e hortaliças devido à intensa manipulação durante as etapas de processamento e aos fatores extrínsecos, como a temperatura de armazenamento. Pode-se destacar, dentre os riscos potenciais, a ausência de uma etapa crítica que promova a destruição de microrganismos, uma vez que tais produtos são normalmente consumidos crus, a possivel ocorrência de

\footnotetext{
1. Recebido para publicação em 08/10/2003. Aceito para publicação em 24/06/2004 (001234).

2. Departamento Pré-Processamento de Produtos Agropecuários - FEAGRI/ UNICAMP, Caixa Postal 6011, CEP: 13083-875, Campinas-SP. E-mail: lrantoniolli@yahoo.com.br, benedeti@agr.unicamp.br

3. EMBRAPA Agroindústria Tropical, Caixa Postal 13761, CEP: 60511 110, Fortaleza-CE.E-mail: sa@cnpat.embrapa.br, fatima@cnpat.embrapa.br * A quem a correspondência deve ser enviada.
}

temperaturas elevadas durante distribuição e comercialização, além da existência de microrganismos que se multiplicam sob baixas temperaturas [5].

As fontes de contaminação microbiológica dos produtos vegetais são diversas, iniciando-se na fase de produção e prolongando-se durante as etapas de colheita, manuseio, transporte e comercialização [16]. O processamento mínimo favorece a contaminação dos alimentos em razão do intenso manuseio e do aumento de injúrias no tecido vegetal [18]. O aumento na taxa de deterioração do fruto é decorrente da transferência da microbiota da casca para a polpa, onde os microrganismos encontram condições favoráveis ao seu crescimento [2]. Dessa forma, a sanitização consiste numa etapa de relevância no processamento mínimo, sendo o cloro, nas suas várias formas, o sanitizante mais utilizado em alimentos até o presente momento [4, 10].

Apesar de sua eficiência, a possibilidade de futuras restrições quanto à utilização do cloro, associada às novas tendências na preservação de alimentos conduz à necessidade de busca por tratamentos alternativos, como os antimicrobianos naturais. O efeito antimicrobiano da vanilina (4-hydroxy-3-methoxybenzaldehyde), assim como de vários outros extratos vegetais, ainda não é bem compreendido; no entanto, tais substâncias parecem ser eficientes na conservação de sucos e purês de frutas [1, 12].

A adição de vanilina $2000 \mathrm{mg} \cdot \mathrm{L}^{-1}$ ao purê de maçã inibiu o crescimento de Saccharomyces cerevisae, 
Zygosaccharomyces rouxii, Zygosaccharomyces bailii e Debaryomyces hansenii, em população de $10^{4}$ células.g-1 ${ }^{-1}$, durante 40 dias de armazenamento a $27^{\circ} \mathrm{C}$ [7].

De acordo com CERRUTTI, ALZAMORA \& VIDALES [8], não foi detectado crescimento de microrganismos aeróbios mesófilos em purê de morango com adição de vanilina $3000 \mathrm{mg} . \mathrm{L}^{-1}$, constatando-se um aumento, em um período de 2 dias, na população destes microrganismos nas amostras controle. Verificou-se, ao quarto dia do armazenamento, uma redução na ordem de dois ciclos logarítmicos na população de bolores e leveduras presentes no purê com vanilina, ao passo que na ausência deste composto a população, inicialmente de $10^{4} \mathrm{UFC}^{-g^{-1}}$, atingiu valores de $10^{7} \mathrm{UFC}^{-g^{-1}}$ após 4 dias de armazenamento a $27^{\circ} \mathrm{C}$.

De forma semelhante, CASTAÑÓN, ARGAIZ \& MALOLÓPEZ [6] verificaram inibição no crescimento de microrganismos aeróbios mesófilos e de bolores e leveduras em purê de banana com adição de vanilina 3000mg. $\mathrm{L}^{-1} \mathrm{e}$ armazenado durante 60 dias sob temperaturas de 15, 25 e $35^{\circ} \mathrm{C}$.

Objetivou-se, neste trabalho, a avaliação dos efeitos da vanilina como agente antimicrobiano, bem como a avaliação do nível de injúria física, decorrente do corte, como fator de contaminação inicial em abacaxi 'Pérola' minimamente processado.

\section{2 - MATERIAL E MÉTODOS}

Abacaxis 'Pérola', provenientes de Mari-PB, foram pré-selecionados e transportados à Planta de Processamento Mínimo da EMBRAPA Agroindústria Tropical, Fortaleza-CE, onde foram padronizados quanto ao tamanho e à coloração da casca, lavados com água corrente e detergente neutro e sanitizados com hipoclorito de sódio ( $\mathrm{NaOCl}$ ) 200mg. $\mathrm{L}^{-1}$, em tanque de aço inoxidável com movimentação de água, durante 2 minutos. Em seguida, os frutos foram acondicionados em caixas plásticas previamente lavadas e higienizadas $(\mathrm{NaOCl}$ 200mg. $\mathrm{L}^{-1}$ ) e armazenados, durante aproximadamente 24 horas, em câmara refrigerada mantida à temperatura de $12 \pm 1^{\circ} \mathrm{C}$. Para a obtenção de abacaxi MP em fatias e cubos, os frutos foram descascados e fatiados mecanicamente. As fatias, com aproximadamente $1 \mathrm{~cm}$ de espessura, tiveram o cilindro central removido utilizando-se da faca circular do descascador pneumático. Os cubos foram obtidos através do corte das fatias em 4 seções iguais.

Ambos os tipos de corte foram acondicionados, separadamente, em caixas plásticas perfuradas e submetidos ao tratamento de imersão, durante 30 segundos, em água (controle) ou soluções de vanilina 3000 ou $5000 \mathrm{mg} . \mathrm{L}^{-1}$, mantidas à temperatura de $10^{\circ} \mathrm{C}$. Decorrido o tempo de imersão, as fatias e os cubos permaneceram em repouso durante aproximadamente 2 minutos para drenagem do excesso de líquido. Em seguida foram acondicionados em embalagens de polietileno tereftalato e armazenados sob temperatura de $4 \pm 1^{\circ} \mathrm{C}$ durante 12 dias. Todo o processamento foi conduzido em ambiente refrigerado, com temperaturas variando entre 12 e $15^{\circ} \mathrm{C}$. Para se evitar a contaminação cruzada, foram utilizadas luvas, máscaras e toucas descartáveis.

O abacaxi MP foi avaliado microbiologicamente em intervalos de três dias, durante 12 dias de armazenamento refrigerado. As amostras destinadas à avaliação no tempo 0 foram retiradas imediatamente após o corte em fatias e cubos. As análises microbiológicas envolveram a contagem de microrganismos aeróbios mesófilos e de bolores e leveduras e a determinação de coliformes totais $\left(35^{\circ} \mathrm{C}\right)$ e coliformes fecais $\left(45^{\circ} \mathrm{C}\right)$. As análises foram realizadas conforme metodologia descrita no Manual de Análises Microbiológicas de Alimentos [15] e no Compendium of Methods for the Microbiological Examination of Foods, "APHA" [9].

A população de microrganismos aeróbios mesófilos foi quantificada pelo método de semeadura em profundidade em ágar para contagem padrão (Merck, EUA). As placas foram incubadas a $35^{\circ} \mathrm{C}$, por $24-48$ horas, e o resultado expresso em unidades formadoras de colônia por grama do produto (UFC. g $^{-1}$ ). A população de bolores e leveduras foi determinada pelo método de semeadura em superfície em ágar batata dextrosado acidificado (Merck, EUA). As placas foram incubadas (invertidas) a $21-22^{\circ} \mathrm{C}$ por $3-5$ dias. O resultado foi expresso em unidades formadoras de colônia por grama do produto (UFC. $\mathrm{g}^{-1}$ ). A determinação do número mais provável de coliformes totais (NMP. $\mathrm{g}^{-1}$ ) foi realizada através de teste presuntivo em caldo lauril sulfato triptose (Difco, EUA) incubado a $35^{\circ} \mathrm{C}$ por $24-48$ horas e de teste confirmativo em caldo bile verde brilhante, a $35^{\circ} \mathrm{C}$ por 24-48 horas. Em seguida, foi determinado o número mais provável de coliformes fecais em caldo Escherichia coli (EC, Difco, EUA) incubado a $45,5^{\circ} \mathrm{C}$ por 24 horas.

O delineamento experimental adotado foi o inteiramente casualizado com parcelas subdivididas no tempo, onde se estudou a interação entre os fatores: concentração de vanilina $\left(0,3000\right.$ e $\left.5000 \mathrm{mg} . \mathrm{L}^{-1}\right)$, corte (fatia e cubo) e tempo (0, 3, 6, 9 e 12 dias), com 2 repetições. Os valores foram transformados em $\log (\mathrm{x})$ e submetidos à análise de variância, sendo as médias comparadas pelo teste de Tukey a 5\% de probabilidade.

\section{3 - RESULTADOS E DISCUSSÃO}

Não foram detectados coliformes totais e fecais nas amostras dos diferentes tratamentos durante 12 dias de armazenamento refrigerado, o que sugere ausência de tais microrganismos na matéria-prima e indica que o processamento foi conduzido sob condições higiênico-sanitárias adequadas. Este resultado atende à Legislação Brasileira, ANVISA - Resolução RDC-12 [3], que estabelece o limite de $5 \times 10^{2}$ UFC de coliformes fecais por grama, para frutas, produtos de frutas e similares - frescas, in natura, preparadas (descascadas ou selecionadas ou fracionadas), sanitizadas, refrigeradas ou congeladas para consumo direto.

A contagem inicial, tanto para microrganismos aeróbios mesófilos quanto para bolores e leveduras, es- 
teve na ordem de $10^{3}$ e $10^{4} \mathrm{UFC} \cdot \mathrm{g}^{-1}$, nas fatias e cubos, respectivamente (Figuras $1 \mathrm{~A} e \mathrm{e}$ ). É provável que as populações observadas no abacaxi MP não resultem única e exclusivamente da contaminação microbiológica durante o processamento, uma vez que tais microrganismos fazem parte da microbiota endofítica do abacaxi. ROBBS [13], avaliando a distribuição e a oscilação da população de leveduras nas diversas fases de formação e desenvolvimento do abacaxi (flor, frutilho e fruto), observou que as populações variaram de $2,2 \times 10^{5}$ a $1,1 \times 10^{6} \mathrm{UFC}_{\mathrm{g}} \mathrm{g}^{-1}$ nas flores e frutos. Houve participação significativa da população de bactérias gram-negativas na flora microbiana de flores e frutos imaturos. A população de bolores aumentou na fase de floração até o início da formação dos frutos, permanecendo estável posteriormente. As bactérias lácticas representaram uma pequena parte da população microbiana das flores, com declínio após o início da formação dos frutos. As bactérias acéticas foram detectadas somente em frutos maduros. WEBER et al. [17] observaram populações de bactérias endofíticas na ordem de $10^{2} \mathrm{UFC}^{-1} \mathrm{~g}^{-1} \mathrm{em}$ frutos parcialmente maduros de abacaxizeiro. De acordo com SARZI, DURIGAN \& ROSSI JÚNIOR [14], a população de microrganismos aeróbios mesófilos detectada em abacaxi 'Pérola' MP, após 7 dias de armazenamento a $9^{\circ} \mathrm{C}\left(10^{5} \mathrm{UFC} \mathrm{g}^{-1}\right)$, foi coincidente com a flora detectada nos frutos frescos.
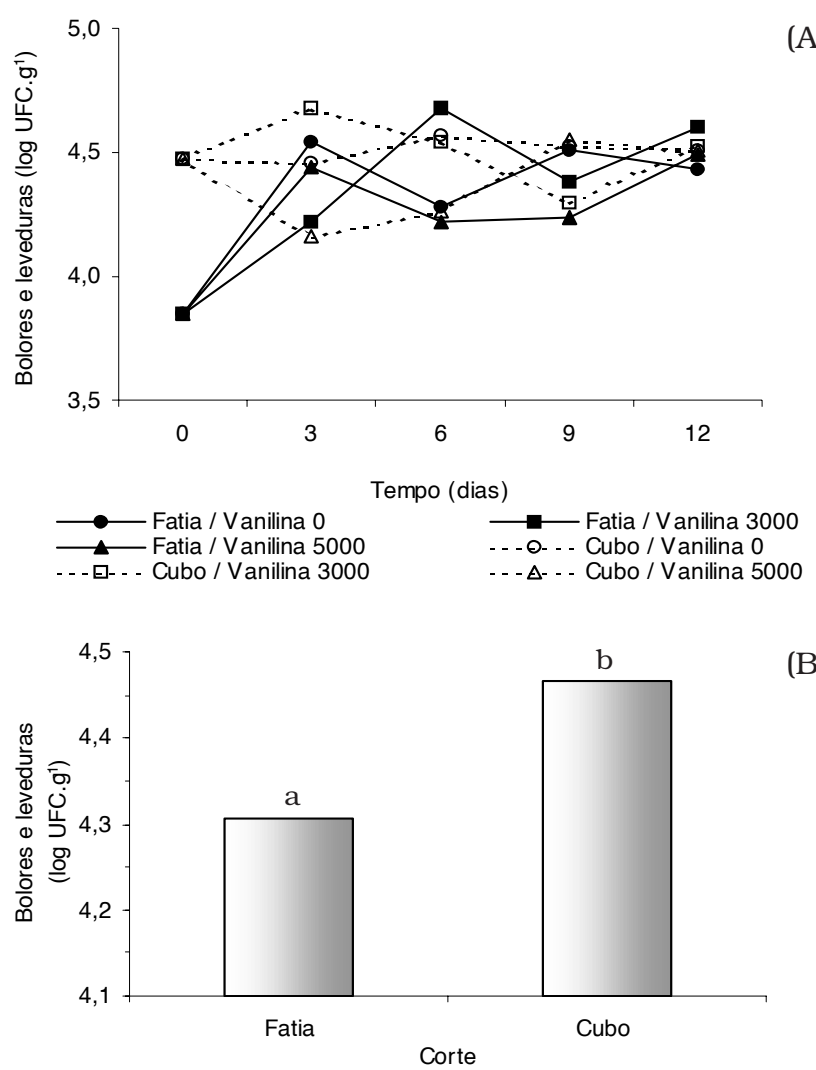

FIGURA 1. Bolores e leveduras em abacaxi 'Pérola' minimamente processado submetido ao tratamento com vanilina e armazenado a $4 \pm 1{ }^{\circ} \mathrm{C}$ durante 12 dias. (Valores médios (A); Barras verticais indicam a diferença mínima significativa $(\mathrm{P} \leq 0,05)(\mathbf{B}))$.
A interação entre os fatores avaliados (concentração de vanilina, corte e tempo) não foi significativa para a população de bolores e leveduras, no entanto, as contagens médias (Figura 1A) indicam que a população de bolores e leveduras observada nas fatias, ao tempo 0 , foi cerca de 1 ciclo logarítmico inferior àquela constatada nos cubos, verificando-se, a partir do $3^{\circ}$ dia, populações semelhantes nas amostras provenientes de todos os tratamentos. Independente da concentração de vanilina e do tempo, os abacaxis minimamente processados na forma de fatias apresentaram população de bolores e leveduras estatisticamente inferior àquela encontrada nos frutos cortados em cubos (Figura 1B). Embora a diferença entre as populações encontradas nas fatias e nos cubos seja pequena $(4,30$ e 4,54log $\mathrm{UFC} . \mathrm{g}^{-1}$, respectivamente), trabalhos conduzidos por GORNY [11] sugerem que a maior exposição de superfícies desprotegidas, causada pelo corte, conduza à maior contaminação microbiana.

Semelhante ao observado anteriormente, não foi constatada interação significativa entre os fatores: concentração de vanilina, corte e tempo para a população de microrganismos aeróbios mesófilos; no entanto, as contagens médias indicam que as fatias submetidas ao tratamento com vanilina 5000mg. $\mathrm{L}^{-1}$ apresentaram as menores populações até o $12^{\circ}$ dia de armazenamento refrigerado (Figura 2). Independente do tempo, constatou-se que a vanilina $\left(5000 \mathrm{mg} . \mathrm{L}^{-1}\right)$ proporcionou população estatisticamente inferior nos frutos cortados em fatias quando comparado àqueles cortados em cubos. Tal comportamento não foi observado no controle, bem como quando usada menor concentração do agente antimicrobiano. Verificou-se que, embora significativamente diferentes, as populações de microrganismos aeróbios mesófilos encontradas nas fatias e nos cubos submetidos ao tratamento com vanilina 5000mg. $\mathrm{L}^{-1}$ encontravam-se na ordem de $10^{3} \mathrm{UFC}^{-g^{-1}}$. As populações observadas nos demais tratamentos, em ambos os tipos de corte, encontravam-se na ordem de $10^{4}$ UFC. $^{-1}$ (Figura 3A).
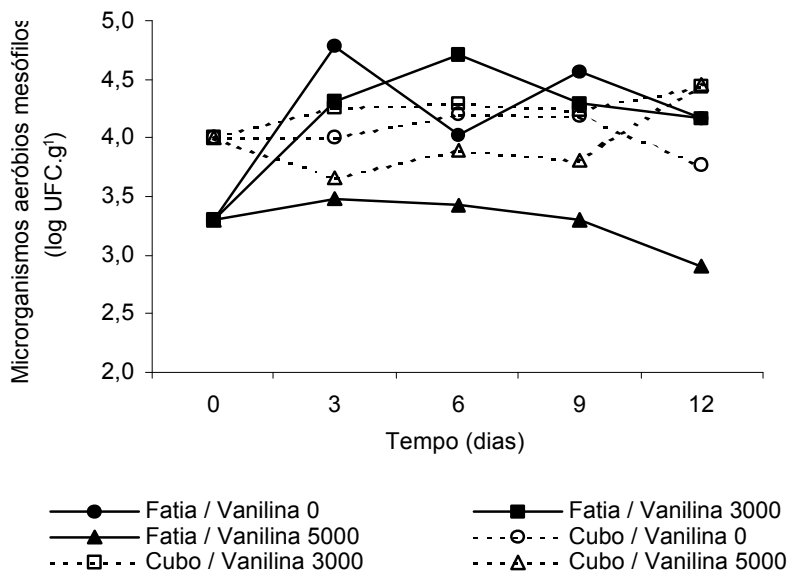

FIGURA 2. Microrganismos aeróbios mesófilos em abacaxi 'Pérola' minimamente processado em fatias e cubos e submetidos ao tratamento com vanilina (Valores médios). 
A população de microrganismos aeróbios mesófilos presente nas fatias apresentou curva típica de crescimento, caracterizada pelas fases de latência, exponencial ou logarítmica, estacionária e de declínio ou morte, ao passo que a população de microrganismos aeróbios mesófilos presente nos cubos manteve-se praticamente inalterada durante os 12 dias de armazenamento refrigerado, com valores oscilando entre 3,97 e 4,22 log UFC. $\mathrm{g}^{-1}$. As populações diferiram estatisticamente entre si no início e ao término do armazenamento, quando as populações de microrganismos aeróbios mesófilos foram inferiores nas fatias (Figura 3B).
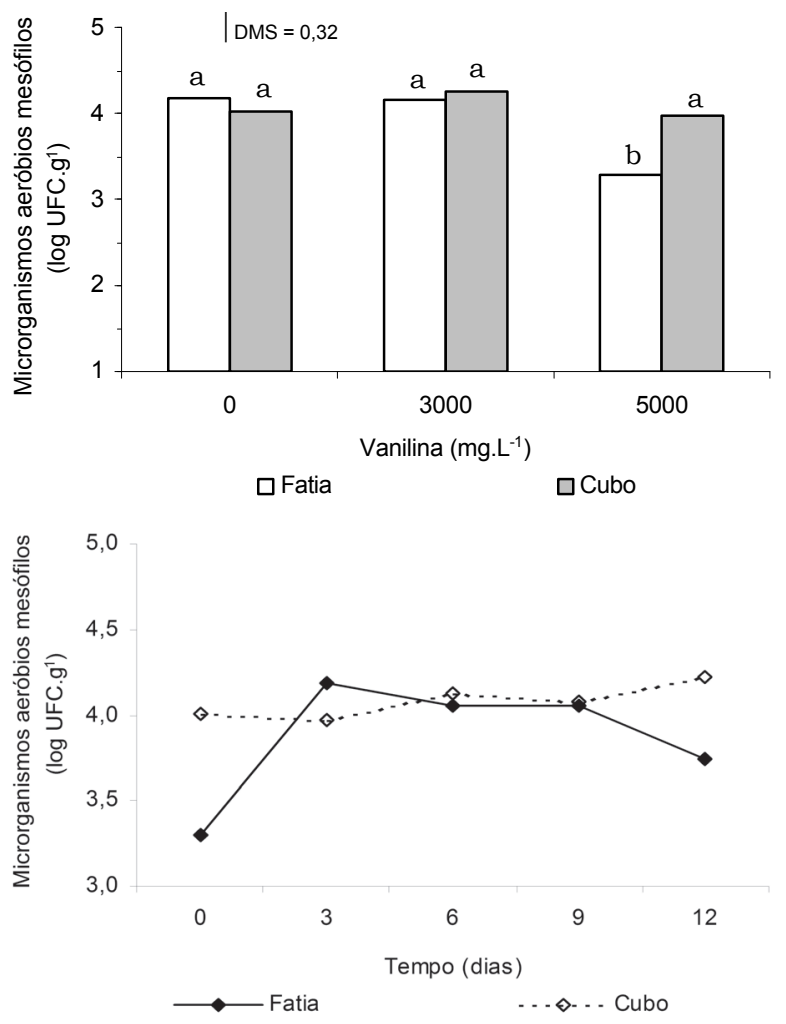

FIGURA 3. Microrganismos aeróbios mesófilos em abacaxi 'Pérola' minimamente processado submetido ao tratamento com vanilina e armazenado a $4 \pm 1^{\circ} \mathrm{C}$ durante 12 dias. Barras verticais indicam a diferença mínima significativa $(\mathrm{P} \leq 0,05)$.

Embora a utilização de vanilina 5000mg. $\mathrm{L}^{-1}$ tenha propiciado menores populações de microrganismos aeróbios mesófilos no abacaxi MP, verificou-se, de modo geral, que a microbiota presente nas amostras oscilou entre $10^{3}$ e $10^{4} \mathrm{UFC}^{-1} \mathrm{~g}^{-1}$ durante todo o armazenamento refrigerado, independente do tipo de corte e do tratamento a que foram submetidas. A manutenção da população de microrganismos aeróbios mesófilos e de bolores e leveduras em niveis praticamente inalterados talvez seja melhor explicada como resultado do armazenamento sob baixas temperaturas $\left(4 \pm 1^{\circ} \mathrm{C}\right)$, do que como efeito do tratamento com vanilina.

Embora não tenha sido realizada análise sensorial, constatou-se que a vanilina, nas concentrações utiliza- das, conferiu um forte aroma de baunilha, característico do produto, ao abacaxi minimamente processado.

\section{4 - CONCLUSÕES}

- A utilização de vanilina não é eficiente no controle do crescimento da população de microrganismos aeróbios mesófilos e de bolores e leveduras em abacaxi 'Pérola' minimamente processado.

- Embora em baixos níveis, a injúria física parece favorecer a contaminação inicial do produto minimamente processado.

\section{5 - REFERÊNCIAS BIBLIOGRÁGICAS}

[1] BEUCHAT, L.R.; GOLDEN, D.A. Antimicrobial occurring naturally in foods. Food Technology, v. 43, n. 1, p. 134-142, 1989.

[2] BRACKETT, R.E. Microbiological consequences of minimally processed fruits and vegetables. Journal of Food Quality, v. 10, n. 3, p. 195-206, 1987.

[3] BRASIL. Resolução RDC no 12, de 02 de janeiro de 2001. Aprova regulamento técnico sobre os padrões microbiológicos para alimentos. Ministério da Saúde. Agência Nacional de Vigilância Sanitária. Disponível em: http://www.anvisa.gov.br/legis/resol/12-01rda.htm. Acesso em: 14 maio 2002.

[4] BRECHT, J.K.; SABAA-SRUR, A.U.O.; SARGENT, S.A.; BENDER, R.J. Hypochlorite inhibition of enzymic browning of cut vegetables and fruit. Acta Horticulturae, n. 343, p. 341-344, 1993.

[5] CANTWELL, M. Food safety. I. Microbiological concerns. In: FRESH-CUT PRODUCTS: MAINTAINING QUALITY AND SAFETY, 5., Davis, 1999. Annual Workshop. Davis: University of California, 1998. Section 8a, p. 1-2.

[6] CASTAÑÓN, X.; ARGAIZ, A.; MALO-LÓPEZ, A. Effect of storage temperature on the microbial and color stability of banana purée with addition of vanillin or potassium sorbate. Food Science and Technology International, v. 5, n. 1, p. 51-58, 1999.

[7] CERRUTTI, P.; ALZAMORA, S.M. Inhibitory effects of vanillin on some food spoilage yeasts in laboratory media and fruit purées. International Journal of Food Microbiology, v. 29, n. 2-3, p. 379-386, 1996.

[8] CERRUTTI, P.; ALZAMORA, S.M.; VIDALES, S.L. Vanillin as an antimicrobial for producing shelf-stable strawberry puree. Journal of Food Science, v. 62, n. 3, p. 608610, 1997.

[9] DOWNES, F.P.; ITO, K. Compendium of methods for the microbiological examination of foods. Washington: AMERICAN PUBLIC HEALTH ASSOCIATION APHA, 2001. 676p.

[10] DYCHDALA, G.R. Chlorine and chlorine compounds. In: Desinfection sterilization and preservation. 4.ed. 1991. p. 131-151.

[11] GORNY, J. Fresh-cut product preparation. In: FRESHCUT PRODUCTS: MAINTAINING QUALITY AND SAFETY, 5., Davis, 1999. Annual Workshop. Davis: University of California, 1998. Section 5a, p. 1-5.

[12] JAY, M.J.; RIVERS, G.M. Antimicrobial activity of some food flavoring compounds. Journal of Food Safety, v. 6, n. 2, p. 129-139, 1984.

[13] ROBBS, P.G. Ecologia e taxonomia de leveduras associadas a uma plantação de abacaxi no Estado do 
Rio de Janeiro. Rio de Janeiro, 1986. 241p. Tese de Doutorado - Instituto de Microbiologia, Universidade Federal do Rio de Janeiro.

[14] SARZI, B.; DURIGAN, J.F.; ROSSI JÚNIOR, O.D. Temperatura e tipo de preparo na conservação de produto minimamente processado de abacaxi 'Pérola'. Revista Brasileira de Fruticultura, v. 24, n. 2, p. 376-380, 2002.

[15] SILVA, N.; JUNQUEIRA, V.C.A.; SILVEIRA, N.F.A. Manual de métodos de análise microbiológica de alimentos. São Paulo: VARELLA, 1997. 295p.

[16] VANETTI, M.C.D. Controle microbiológico e higiene no processamento mínimo. In: ENCONTRO NACIONAL SOBRE PROCESSAMENTO MÍNIMO DE FRUTAS E HORTALIÇAS, 2., Viçosa, 2000. Palestras. Viçosa: UFV, 2000. p. 44-51.

[17] WEBER, O.B.; BALDANI, V.L.D.; TEIXEIRA, K.R.S.; KIRCHHOF, G.; BALDANI, J.I.; DOBEREINER, J.
Isolation and characterization of diazotrophic bacteria from banana and pineapple plants. Plant and Soil, n. 210, p. 103-113, 1999.

[18] WILEY, R.C. Minimally processed refrigerated fruits and vegetables. London: Chapman \& Hall, 1994. 357p.

\section{6 - AGRADECIMENTOS}

À Fundação de Amparo à Pesquisa do Estado de São Paulo (FAPESP) pelo apoio financeiro. À Embrapa Agroindústria Tropical, à Celli Rodrigues Muniz e à Érika H. Franco de Azevedo pela realização das análises microbiológicas, à Claísa A. Silva de Freitas, ao Manoel Alves de Souza Neto e ao Arthur C. Rodrigues de Souza pelo auxílio e disponibilidade na instalação do experimento. 